\title{
Self-stigma and schizophrenia: a cross-sectional study
}

\author{
This article was published in the following Dove Press journal: \\ Neuropsychiatric Disease and Treatment \\ 24 November 2016 \\ Number of times this article has been viewed
}

\author{
Kristyna Vrbova' \\ Jan Prasko' \\ Michaela Holubova ${ }^{1,2}$ \\ Dana Kamaradova' \\ Marie Ociskova' \\ Marketa Marackova' \\ Klara Latalova' \\ Ales Grambal' \\ Milos Slepecky ${ }^{3}$ \\ Marta Zatkova ${ }^{3}$ \\ 'Department of Psychiatry, Faculty \\ of Medicine and Dentistry, Palacky \\ University in Olomouc, University \\ Hospital Olomouc, Olomouc, \\ ${ }^{2}$ Department of Psychiatry, Hospital \\ Liberec, Liberec, Czech Republic; \\ ${ }^{3}$ Department of Psychology Sciences, \\ Faculty of Social Science and Health \\ Care, Constantine the Philosopher \\ University, Nitra, Slovak Republic
}

Correspondence: Jan Prasko Department of Psychiatry, Faculty of Medicine and Dentistry, Palacky University in Olomouc and University Hospital Olomouc, I.P.Pavlova 6, 77520 Olomouc, Czech Republic Email praskojan@seznam.cz
Objective: The aim of this study was to investigate the degree of self-stigma in schizophrenia and its association with clinical and demographic factors.

Patients and methods: A total of 197 outpatients (54.3\% females) diagnosed with schizophrenia spectrum disorders (schizophrenia, schizoaffective disorder, delusional disorder) according to International Classification of Diseases - tenth edition participated in the study. The mean age of the patients was $40.10 \pm 11.49$ years. All individuals completed the Internalized Stigma of Mental Illness (ISMI) scale and a demographic questionnaire. The disorder severity was assessed by both a psychiatrist (the objective version of Clinical Global Impression - severity scale [objCGI-S]) and the patients (the subjective version of Clinical Global Impression - severity scale [subjCGI-S]). Treatment with antipsychotics stabilized the patients.

Results: The overall level of self-stigma measured by the total score of the ISMI was $63.32 \pm 13.59$. The total score of the ISMI positively correlated with the severity of the disorder measured by the objCGI-S and subjCGI-S. In addition, self-stigma positively correlated with the treatment duration and the number of psychiatric hospitalizations. The backward stepwise regression was applied to identify the most significant factors connected to self-stigma. The regression analysis identified the following regressors as the most relevant to self-stigma: the number of previous psychiatric hospitalizations, the severity of the disorder rated by a psychiatrist, and the difference between the objective rating and the subjective rating of the severity of the disorder.

Conclusion: Outpatients with schizophrenia spectrum disorders, who have undergone a higher number of psychiatric hospitalizations, who dispose of a higher severity of the disorder and show a higher discrepancy between their rating of the severity and the psychiatric rating, showed a greater degree of self-stigma. The management of self-stigma in patients with schizophrenia should be implemented in the routine care.

Keywords: schizophrenia, self-stigma, duration of the treatment, number of hospitalizations

\section{Introduction}

Most individuals diagnosed with schizophrenia must cope with some form of stigmatization during their lives. ${ }^{1,2}$ Different types of public stigma, self-stigma, and label avoidance may have profoundly negative consequences for individuals with a mental disorder. ${ }^{3-8}$ The stigma consists of two basic factors, negative attitudes and discrimination. The stigma then operates at three levels, public (ie, how the stigma manifests in a given society, culture, media, everyday habits, and attitudes), structural (institutional, ie, at the level of functioning of organizations, agencies, and employers), and personal (ie, how patients perceive themselves). ${ }^{9}$

Significant terminological distinction exists between the public stigma (when the general population supports the prejudices and discriminates against people with 
mental illness) and the personal stigma, which also consists of the following three parts: 1) the perceived stigma; 2) the experienced stigma; and 3) the self-stigma, ie, how stigma itself accepted. ${ }^{10}$ The perceived or anticipated stigma is associated with patients' beliefs about the attitudes of the general public to the members of stigmatized groups. ${ }^{11}$ The experienced stigma is related to the emotional experience of discrimination. The self-stigma is accompanied by a loss of positive beliefs about themselves, a decrease in self-esteem and self-confidence, and poorer insight among the individuals with psychoses. ${ }^{10,12-16}$

Internalization of the stigma can start when the individuals notice that others begin to act differently to them because of their mental struggles and realize the prejudices that lead to such action. Subsequently, they begin to believe that the views and attitudes toward people with a mental disorder are justified. In the last stage of internalization of the stigma, the patients apply the prejudices to themselves and act according to them. This process leads to the increase in the intensity of symptoms and worse overall prognosis. ${ }^{17,18}$ The stigma affects not only the patients but also their families. Relatives are usually aware of the prejudices of society toward mental illnesses. This awareness can lead to discouraging patients from seeking psychiatric care. Hand in hand with accepting the reality of mental illness often appears the fear of stigmatization. ${ }^{19}$

A meta-analysis of 54 studies performed by Gerlinger et $\mathrm{al}^{20}$ shows that the neighbors' negative perception of stigma affects a significant number of patients with schizophrenia. On average, $64.5 \%$ of the patients feel stigmatized, and up to $55.9 \%$ actually experience stigmatization. According to the authors, the perceived or experienced stigma is associated with more severe depressive symptoms, greater social anxiety and avoidant behavior, low self-confidence, poorer social functioning, and overall lower quality of life. Two other studies have pointed to the relationship between the personal stigma and the social anxiety already during the first psychotic episode..$^{21,22}$ Patients with comorbid social anxiety showed an increased perception of the stigma. ${ }^{21}$

The aim of this study was to investigate the degree of self-stigma in patients with schizophrenia and its association with clinical and demographic factors. According to our hypotheses, the level of self-stigma is linked with, 1) the severity of the disorder, 2) the duration or early onset of the disorder, 3 ) the number of hospitalizations, 4) the employment status, 5) the level of education, and 6) the partner status.

\section{Patients and methods}

\section{Sample}

A total of 197 patients of both sexes, attending outpatient psychiatric facilities in stable condition (they did not require hospitalization, changes in medication, or other therapeutic intervention), participated in the study. The inclusion criteria were as follows:

1) Age: 18-65 years.

2) Diagnosis of schizophrenia spectrum disorders according to International Classification of Diseases - tenth edition. ${ }^{23}$

Patients suffering from severe physical disease, mental retardation, or an organic mental disorder were excluded.

\section{Assessment instruments}

After a short education, the patients completed assessment scales and questionnaires. The severity of illness was determined by a thorough interview with the doctor, who evaluated the severity on the objective version of Clinical Global Impression (CGI) - severity scale (objCGI-S). The following assessment tools were used:

1. The Internalized Stigma of Mental Illness (ISMI) scale: the scale consists of 29 items with a 4-point Likert scale and evaluates five areas of self-stigma - alienation, stereotype endorsement, perceived discrimination, social withdrawal, and stigma resistance. ${ }^{24,25}$ The Czech version of the ISMI scale was standardized by Ocisková et al. ${ }^{26}$ Internal consistency of the Czech text of the scale was excellent (Cronbach's $\alpha=0.91$ ).

2. CGI: the CGI is the assessment of the overall severity of the disorder. ${ }^{27}$ The objCGI-S is an overall evaluation of the patient's mental state by a physician. In the subjective version of CGI - severity scale (subjCGI-S), the patient himself/herself evaluates his/her overall condition. The scale ranges from 1 (normal, with no signs of illness) to 7 (extremely severe symptoms of the disease).

3. Demographic questionnaire contained the basic information: sex, age, marital status, education, employment, disability, age at onset of the disorder, duration of attendance to the psychiatric services, number of hospitalizations, time since last hospitalization, number of visited psychiatrists, medication, and medication discontinuation in the past (on the recommendation of a psychiatrist or willingly).

\section{Statistics and ethics}

The statistical programs Prism 3 (GraphPad Software, Inc., La Jolla, CA, USA) and SPSS 24.0 (SPSS Inc., Chicago, IL, USA) were used for the statistical evaluation of the 
results. Demographic data and the average scores in the scales were evaluated using descriptive statistics (mean, median, standard deviation, and the characteristics of data distribution). Mean values were compared by independent $t$-tests. Relationships between categories were assessed by correlation coefficients. Fisher's exact test was used to verify the relationship between dichotomous variables (sex, marital status, dropout of medication). The importance of each correlation between others was tested by backward stepwise regression. The general rule of selection was that backward stepwise regression tested only variables that were statistically significant in the univariate analysis. All statistical tests were considered acceptable at 5\% level of statistical significance.

The study was approved by the Ethical Committee of the University Hospital Olomouc. The research was conducted according to the latest version of the Declaration of Helsinki and recommendations for good clinical practice. ${ }^{28}$ All patients signed an informed consent form.

\section{Medication management}

All patients were in outpatient care at the psychiatric clinic and were currently in stable condition - they did not require changes in medical treatment or the regimen (hospitalization). Medication was administered according to the recommended guidelines for the treatment of schizophrenia. ${ }^{29}$ A total of 195 patients with psychotic spectrum disorders (99.0\%) reported that they used recommended medication prescribed by an attending psychiatrist. Most of them declared that they were using the medication regularly in prescribed doses ( $n=137 ; 69.5 \%), 58(29.4 \%)$ used medication irregularly, and two patients $(0.01 \%)$ stated that they did not use the medication at all.

\section{Results \\ Description of the sample}

The data were collected in the period from May 2015 to August 2016. The battery of scales was offered to 197 patients with schizophrenia and related psychotic disorders who attended the private psychiatric practices or the outpatient psychiatric ward in Olomouc (overall in 30 outpatient psychiatrists). There were slightly more women than men in the sample $(54.3 \%$ of women $)$. The mean age was $40.1 \pm 11.5$ years. The levels of education were as follows: $23(11.7 \%)$ patients had a primary school education, 52 (26.4\%) had vocational training, 84 (42.6\%) had a secondary education, and $37(18.8 \%)$ had university level of education. One patient did not declare his highest level of education. There were $66.0 \%$ of unemployed patients and $33.5 \%$ worked as employees or were self-employed. Information regarding the employment of one patient was not complete. Overall, $51.8 \%$ of the participants had a full disability pension, $16.8 \%$ had a partial disability pension, and $5.5 \%$ were taking the senior age rent. Regarding marital status, more patients were single $(63.5 \%), 20.3 \%$ were married, and $13.2 \%$ were divorced. Nearly a third of the patients had a partner (29.4\%; Table 1$)$.

Total ISMI score reached $63.3 \pm 13.6$ points. Regarding the severity of the illness, the psychiatrist assessed the current severity of the disorders on average between "mildly ill" to "moderately ill" and the patients in their subjective scale on average between "borderline mentally ill" and "mildly ill". The subjective assessment of the disease severity by the patients differed (was lower) significantly from an objective evaluation (Mann-Whitney [MW] test, $U=11,470$; $P<0.001)$. Still, the subjective and objective assessment of the severity of the disorder significantly correlated with each other (Spearman's $r=0.45, P<0.001$ ).

The primary diagnosis was a schizophrenia spectrum disorder in all 197 patients (139 were diagnosed with schizophrenia, five with delusional disorder, 12 with acute and transient psychotic disorders, and 41 with schizoaffective disorder).

Table I Sample description

\begin{tabular}{ll}
\hline Categories & N or mean \pm SD \\
\hline Number of patients & 197 \\
Age: years & $40.10 \pm 11.49$ \\
Sex: men/women & $90 / 107$ \\
Education: basic/vocational training/ & $23 / 52 / 84 / 37$ \\
secondary/university & \\
Occupation: yes/no & $66 / 130$ \\
Pension: no/full/partial/senior rent & $51 / 102 / 33 / 11$ \\
Marital status: single/married/divorced/widow & $125 / 40 / 26 / 6$ \\
Partner: yes/no & $58 / 139$ \\
Onset of the disorder: years & $26.5 \pm 9.7$ \\
Number of hospitalizations & $3.7 \pm 3.4$ \\
Length of the treatment: years & $13.1 \pm 10.1$ \\
ISMI total score & $63.3 \pm 13.6$ \\
Alienation & $13.1 \pm 3.9$ \\
Stereotype endorsement & $13.8 \pm 3.4$ \\
Perceived discrimination & $10.7 \pm 3.4$ \\
Social withdrawal & $12.8 \pm 3.7$ \\
Stigma resistance & $12.8 \pm 2.4$ \\
objCGI-S & $3.6 \pm 1.3$ \\
subjCGI-S & $2.7 \pm 1.5$ \\
\hline Abrevations: CGI, Clnca &
\end{tabular}

Abbreviations: CGI, Clinical Global Impression; ISMI, the Internalized Stigma of Mental Illness; objCGI-S, the objective version of CGI - severity scale; subjCGI-S, the subjective version of $\mathrm{CGI}$ - severity scale. 


\section{Self-stigma and demographic and clinical factors}

The total score of the ISMI significantly correlated with certain demographic and clinical factors (Table 2). The age of the patient and the age at onset of the disorder did not significantly correlate with the ISMI total score and most of the ISMI domains, with the exception that the age positively correlated with the stereotype endorsement and negatively with the perceived discrimination (Table 2). The number of hospitalizations significantly correlated with the ISMI total score and all domains of the ISMI scale except stigma resistance. In addition, the length of the treatment significantly correlated with the ISMI total score and all its domains except stigma resistance. The objCGI-S significantly positively correlated with the ISMI total score and with domains alienation, perceived discrimination, and social withdrawal, but not with stereotype endorsement or stigma resistance. The subjCGI-S correlated with ISMI total score and all domains of ISMI scale. The difference between objCGI-S and subjCGI-S negatively correlated with all domains of ISMI scale and the ISMI total score except perceived discrimination (Table 2).

The "men and women" differed according to their mean age (the average age of men and women was $37.4 \pm 11.2$ years and $42.4 \pm 11.3$ years, respectively; the independent $t$-test: $t=3.106 ; d f=195 ; P<0.01$ ). The groups did not significantly differ in any other demographic or clinical factor. There were no significant differences in the mean level of self-stigma in the ISMI total score or any ISMI domain according to the sex of the patients (Table 3).

There were 66 patients with "occupation" and 130 patients without one. There were several statistically significant differences between the patients with and without jobs according to their age (unemployed: $41.4 \pm 12.2$ years versus employed: $37.6 \pm 9.5$ years; the independent $t$-test: $t=2.203$; $d f=194 ; P<0.05)$, the mean number of hospitalizations (unemployed: $4.4 \pm 3.8$ versus employed: $2.5 \pm 2.0$; the MW test: $U=3,554 ; P<0.001$ ), the mean duration of the treatment (unemployed: $15.0 \pm 10.4$ years versus employed: 9.4 \pm 8.5 years; the MW test: $U=2,850 ; P<0.001$ ), objCGI-S (unemployed: $3.8 \pm 1.2$ versus employed: $3.1 \pm 1.2$; the $\mathrm{MW}$ test: $U=2,881 ; P<0.001$ ), and subjCGI-S (unemployed: 2.9 \pm 1.6 versus employed: $2.2 \pm 1.3$; the MW test: $U=3,208$; $P<0.01)$. There was also a statistically significant difference according to the occupation in the self-stigma measured by the ISMI total score and in the domains, stereotype endorsement and social withdrawal (Table 3). The employed patients stigmatized themselves less than the unemployed patients.

The differences in self-stigma according to the "marital status" of the patients were calculated without widows because this category was not sufficiently large (there were only six widowed individuals). There was a statistically significant difference between subgroups according to the marital status, in their mean age (one-way analysis of variance [ANOVA]: $F=0.85 ; d f=190 ; P<0.001)$. The Bonferroni's multiple comparison test showed that the differences were between the singles and the married patients $(P<0.001)$ and the singles and the divorced patients $(P<0.001)$, but not between the married and divorced patients. There were also statistically significant differences between the subgroups of the patients divided according to the marital status at the onset of the disorder (one-way ANOVA: $F=26.07$; $d f=189 ; P<0.001)$. The patients did not significantly differ in both the mean scores of the objCGI-S (the singles scored

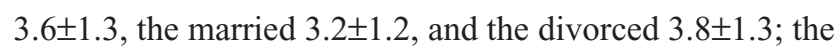
Kruskal - Wallis $[\mathrm{KW}]$ test $=3.574$; non significant $[\mathrm{ns}]$ ) and the subjCGI-S (the singles reached 2.6 \pm 1.5 , the married 2.6 \pm 1.4 , and the divorced 3.0 \pm 1.6 ; the $\mathrm{KW}$ test: $=1.186$; ns) according to the marital status. There was no statistically significant difference between the subgroups according to the marital status in the mean ISMI scores (Table 3).

Table 2 Correlation coefficients and their statistical significance between the ISMI total score and selected demographic or clinical factors (Spearman's $r$ )

\begin{tabular}{|c|c|c|c|c|c|c|}
\hline Factor & ISMI total score & Alienation & $\begin{array}{l}\text { Stereotype } \\
\text { endorsement }\end{array}$ & $\begin{array}{l}\text { Perceived } \\
\text { discrimination }\end{array}$ & $\begin{array}{l}\text { Social } \\
\text { withdrawal }\end{array}$ & $\begin{array}{l}\text { Stigma } \\
\text { resistance }\end{array}$ \\
\hline Age & 0.11 & 0.04 & $0.16^{*}$ & 0.02 & 0.09 & -0.02 \\
\hline Onset of the disorder & -0.04 & -0.11 & -0.01 & $-0.14 *$ & -0.05 & 0.01 \\
\hline Number of hospitalizations & $0.21 * *$ & $0.24 * * *$ & $0.14 *$ & $0.31 * * *$ & $0.22 * *$ & -0.10 \\
\hline Length of the treatment & $0.18^{*}$ & $0.19 * *$ & $0.25 * * *$ & $0.23 * *$ & $0.21 * *$ & 0.01 \\
\hline objCGI-S & $0.20 * *$ & $0.15^{*}$ & 0.13 & $0.22 * *$ & $0.19 * *$ & 0.05 \\
\hline subjCGI-S & $0.35 * * *$ & $0.38 * * *$ & $0.32 * * *$ & $0.23 * *$ & $0.38 * * *$ & $0.18^{*}$ \\
\hline Difference of objCGI-S-subjCGI-S & $-0.17 *$ & $-0.25 * * *$ & $-0.18 * *$ & -0.06 & $-0.21 * *$ & $-0.19 * *$ \\
\hline
\end{tabular}

Notes: $* p<0.05 ; * * p<0.01 ; * * * p<0.001$

Abbreviations: CGI, Clinical Global Impression; ISMI, the Internalized Stigma of Mental Illness; objCGI-S, the objective version of CGI - severity scale; subjCGI-S, the subjective version of $\mathrm{CGI}$ - severity scale. 


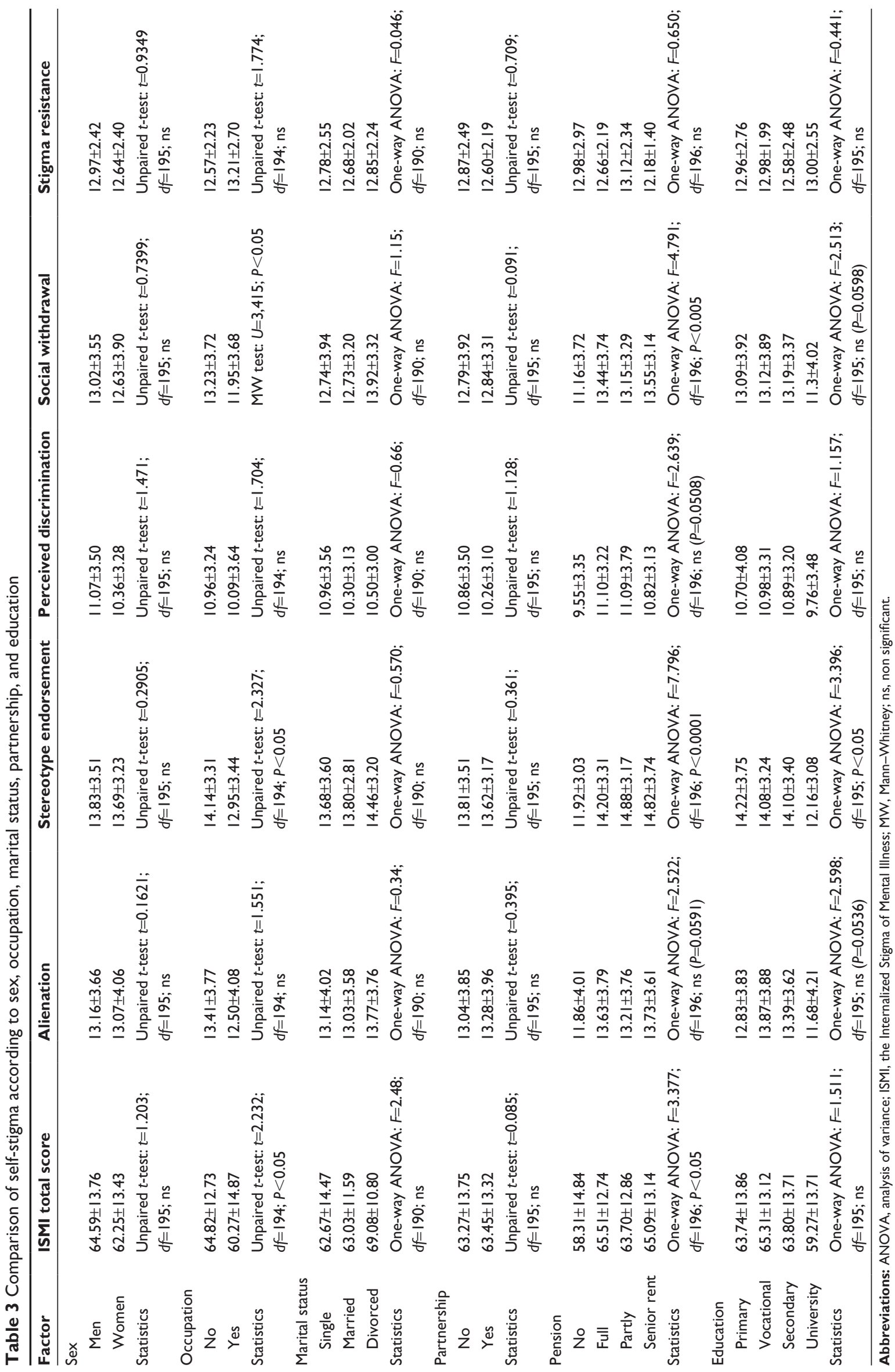


A total of 58 patients had a partner during the collection of the data. The patients, who had a "partner", were older (the individuals without a partner had the mean age of $37.9 \pm 11.4$ years versus the patients with a partner had the mean age of $45.5 \pm 9.8$ years; the independent $t$-test: $t=4.462$; $d f=195 ; P<0.001$ ), their disorder started later in life (without a partner, the average age at the beginning of the disorder was $25.0 \pm 8.7$ years versus with a partner mean age was $30.2 \pm 10.8$ years; MW test; $U=2,754 ; P<0.001)$. There were no significant differences according to the partnership in the average number of the hospitalizations, the duration of the treatment, and the objective or subjective measure of the severity of the disorder (all MW tests: ns). The partnership had no effect on the self-stigma measured by the ISMI scale (Table 3).

There were only 51 patients without any "pension" or rent in the sample (Table 1). There was a significant difference in the age according to the pension status in the subgroups (the mean age in the patients without the disability pension was $34.9 \pm 11.2$ years, in the full disability pension $40.8 \pm 9.2$ years, in the partial disability pension $38.4 \pm 9.0$, and in the senior rent $63.2 \pm 10.0$ years; one-way ANOVA: $F=25.77 ; d f=196 ; P<0.001)$. The Bonferroni's multiple comparison test showed that the significant difference between the age was in comparison to the subgroups of the senior rent and all another group (all $P<0.001$ ) and among the patients without the pension and the patients with the full disability pension $(P<0.01)$.

There were also statistically significant differences between the subgroups divided according to the pension status in the number of the hospitalizations. The patients without any pension were hospitalized $1.8 \pm 1.5$ times, the patients with the full disability pension $4.8 \pm 3.0$ times, the patients with the partial disability pension $3.3 \pm 2.5$ times, and the patients with the senior rent $4.2 \pm 2.5$ times (the KW test: $=35.57 ; P<0.001$ ). The Dunn's multiple comparison test showed that the differences were between the group of the patients without the pension and other groups with all types of a pension, or rent (all: $P<0.05$ ). In addition, there were statistically significant differences between the subgroups of patients divided according to their pension status in length of the treatment. The patients without any pension had been treated for $6.4 \pm 8.4$ years, the full pensioned patients $14.8 \pm 8.4$ years, the partially pensioned patients $12.9 \pm 7.8$ years, and the senior rent patients $29.6 \pm 13.4$ years (the KW test: $=53.05 ; P<0.001$ ). The Dunn's multiple comparison test showed that the differences were between the group without the pension and all other type pension groups (all three comparisons: $P<0.001)$ and the senior rent group and both pension groups (both: $P<0.05$ ).

There were also significant differences in the objectively rated severity of the disorder between the groups divided according to the pension status. The patients without any pension were rated by their psychiatrists with the mean score of $2.8 \pm 1.2$, those with the full disability pension with the average rating of $4.0 \pm 1.2$, the individuals with the partial disability pension with the mean rating of 3.6 \pm 1.1 , and those with the senior rent with the mean rating of $3.7 \pm 1.4$ (the KW test: $=30.4 ; P<0.001)$. The Dunn's multiple comparison test showed that the differences were only in the group of the patients without any pension, the group with the full disability pension $(P<0.05)$, and the group with the partial disability pension $(P<0.05)$, but not in other intergroup comparisons.

The subjCGI-S showed significant differences among the groups divided according to the pension, too. The patients without any pension rated their severity of the disorders as $1.9 \pm 1.2$, the patients with the full disability pension as $2.9 \pm 1.5$, the patients with the partial disability pension as 3.1 \pm 1.6 , and the patients with the senior rent as $2.4 \pm 1.4$ (the KW test: $=17.97 ; P<0.001$ ). According to the Dunn's multiple comparison test, the differences were only in the group without any pension, the group with the full disability pension $(P<0.05)$, and the group with a partial disability pension $(P<0.05)$, but not in other intergroup comparisons.

The difference between the ISMI total score in groups divided according to the pension status reached statistical significance (Table 3). According to the Bonferroni's multiple comparison test, the difference was only among patients without any pension and the patients with the full disability pension $(P<0.05)$, but not in other intergroup comparisons. From the domains of the ISMI scale, stereotype endorsement showed the highest difference between the groups divided according to the pension status (Table 3 ) and the Bonferroni's multiple comparison test showed that there were significant differences between the group without any pension and all other groups with the pension (with the full disability pension: $P<0.001$; with the partial disability pension: $P<0.001$; with the senior rent: $P<0.05)$. Furthermore, there were significant differences in the domain of the ISMI scale, social withdrawal, between the groups divided according to the pension status (Table 3 ). In the Bonferroni's multiple comparison test, the significant difference was only among patients without the pension and 
Table 4 Multiple regression analysis of the ISMI total score as the dependent variable

\begin{tabular}{lllllll}
\hline Model & Regressors & B & SE & $\beta$ & $t$ & Significance \\
\hline 4 & Number of hospitalizations & 0.608 & 0.287 & 0.152 & 2.115 & 0.036 \\
& objCGI & 3.067 & 0.838 & 0.284 & 3.658 & 0.000 \\
& Difference of objCGI - subjCGI & -2.953 & 0.703 & -0.312 & -4.199 & 0.000 \\
\hline
\end{tabular}

Note: ANOVA: $F=10.297 ; d f=189 ; P<0.001$; adjusted $r^{2}=0.129$.

Abbreviations: ANOVA, analysis of variance; CGI, Clinical Global Impression; ISMI, the Internalized Stigma of Mental Illness; objCGI, objective version of CGI; SE, standard error; subjCGI, subjective version of $\mathrm{CGl} ; B$, unstandardized regression coefficient; $\beta$, standardized regression coefficient; $t, t$ statistic.

the patients with the full disability pension, but not in other subgroup interactions.

There were no significant differences between groups divided according to the "education" in the demographical data (age, onset of the disorder, length of the treatment), or the severity of the disorder. The degree of the self-stigma measured by the ISMI total score did not differ according to the level of education, but one domain of the ISMI scale, stereotype endorsement, correlated with the degree of education (Table 3).

\section{Regression analysis}

To identify the most significant variables connected to self-stigma, a multiple regression analysis was carried out, namely backward stepwise regression. As the dependent variable, the ISMI total score was chosen. Independent variables were the number of hospitalizations, the length of the treatment, objCGI-S, subjCGI-S, the difference between the objCGI-S and subjCGI-S, occupation, and pension. The collinearity between objCGI, subjCGI, and difference of objCGI-subjCGI was checked. In multiple regression, the objCGI had the tolerance score of 0.708 and variance inflation factor (VIF) of 1.412; and the difference of objCGI-subjCGI had a tolerance score 0.823 and VIF of 1.214. This result means that both variables are not collinear. The subjCGI was removed at the very beginning of the first step of regression. In the four steps of the backward stepwise regression, three factors remained, and all of them were statistically significant (Table 4).

\section{Discussion}

The aim of this study was to investigate the factors that may be significantly associated with the internalized stigma in patients with schizophrenia and related disorders.

The first hypothesis that "the level of self-stigma is associated with the severity of the disorder" was confirmed. The severity of the disorder, assessed both objectively and subjectively, significantly positively correlated with the total level of self-stigma and also with most domains of this scale. Most research on the topic of self-stigma shows a significant association between the internalized stigma and the overall severity of the disorder in various psychiatric diagnoses including schizophrenia. ${ }^{30-36}$ The results of this study confirm these findings in a group of patients with schizophrenia and related disorders.

The second hypothesis that "the level of self-stigma is linked to the duration or the early onset of the disorder" was not confirmed, if one takes into account only the ISMI total score. The rates of the self-stigma evaluated by the ISMI total score also did not correlate with the age of the patient or the age at the onset of the disorder. This finding is consistent with the results of Holubova et $\mathrm{al}^{35}$ in an outpatient population of patients with schizophrenia spectrum disorders. Only the domain, perceived discrimination negatively correlated with the age at the onset of the disorder. This means that the patients with the early onset of the disorder feel that they are discriminated more often than the individuals with later onset. Early onset of schizophrenia may impair the development of personality and the patient's social roles before he or she can learn how to manage these situations. Earlier onset of schizophrenia is also connected with low self-esteem. ${ }^{14,37}$

The third hypothesis that "the level of self-stigma is associated with the number of hospitalizations" was confirmed. The number of hospitalizations positively correlated with the ISMI total score and also with most of the domains except stigma resistance. In addition, our previous crossover study in various psychiatric diagnoses showed the same result. ${ }^{34}$ It is hard to conclude what was first, whether it was the selfstigma or more frequent hospitalizations. It is impossible to answer such a question from the viewpoint of a crosssectional study. A longitudinal investigation is needed for an adequate answer.

The fourth hypothesis that "the level of the stigma is associated with the employment status" was confirmed according to univariate analysis. The patients with a job had a lower mean of the ISMI total score than the patients without a job. The ISMI total score in connection with the employment status was supported by domains, stereotype endorsement and social withdrawal, which both were significantly higher in the subgroup without a job. The link between self-stigma 
and unemployment was also described in another study. ${ }^{18,38}$ Nevertheless, in the regression analysis, the employment status was removed from the variables.

The fifth hypothesis that "the level of self-stigma is linked to the degree of education" was not confirmed. The mean ISMI total score did not differ among the subgroups with varying degrees of education. The only exception was the domain, stereotype endorsement, which was lower in the patients with the university level of education than in the less educated groups. Our previous study showed that the degree of education might influence self-stigma. ${ }^{34}$

The sixth hypothesis that "the degree of self-stigma is associated with the partnership status" was not confirmed. Neither the ISMI total score nor any of the domains were affected by the partnership status. The result confirms the findings of our previous study. ${ }^{31}$

Looking at the results of the regression analysis, there were three most significant independent factors that passed through, the number of hospitalizations, the objCGI, and the difference between the objCGI and subjCGI. The number of hospitalizations and the objCGI were linked to increased levels of self-stigma. The number of admissions probably reflects the severity of the long-term course of the disorder with severe psychotic episodes and separation from home environment, often with hopelessness and shame. It is not surprising that it might be associated with higher self-stigma. The higher severity of the disorder is often associated with the disapproving behavior of others, and it might increase the self-stigma. The difference between the assessment of the severity of the disorder by the psychiatrist and by the patient may reflect the patient's level of insight. The higher the difference, the lower the self-stigma, and vice versa. This could reflect a controversial issue - the patients with the evaluation closer to that of the therapist show a higher self-stigma.

Other variables, which can explain ISMI values, could be personality traits, especially harm avoidance, and the level of hope and dissociation, as seen in patients with anxiety disorders. ${ }^{30}$ These variables were not involved in the current research but should be included in the studies in future. Another variable, which could influence self-stigma, is the quality of life..$^{39}$ Our group explored this topic in the study by Holubova et al..$^{35}$ The study described a negative impact of self-stigma on the quality of life in outpatients suffering from schizophrenia spectrum disorders.

Many people who develope schizophrenia do not recognize the symptoms and consequences of their illness. Poor insight has frequently been detected in patients with schizophrenia and has been long recognized as a powerful obstacle to the treatment adherence and a risk factor for poorer results of the treatment. ${ }^{40} \mathrm{In}$ contrary, if the patients recognize the symptoms and consequences of their illness it can increase the level of depression, decrease self-esteem, and can increase a risk of suicide. ${ }^{41}$ Self-stigma and difficulties in social cognition and metacognition can be the reasons for insight to convert into negative outcomes. ${ }^{42}$ In Lysaker et al's $\mathrm{s}^{42}$ study of 65 patients suffering from schizophrenia spectrum disorders, the patients with fair insight and moderate depression described a higher level of self-stigma than patients with poor insight and minimal depression. On the other hand, internalized stigma is a barrier to the recovery of patients with schizophrenia. The decreases in self-stigma in the rehabilitation program were correlated with increased self-esteem. ${ }^{43}$ The influence of stigma resistance on the functioning of patients with schizophrenia was studied by Firmin et al. ${ }^{44}$ Their meta-analysis showed a large negative association between stigma resistance and self-stigma, the substantial positive relation between stigma resistance and quality of life, hope, and recovery, and the medium and small relationship between stigma resistance and insight and symptoms of the disorder. Stigma resistance may be a crucial condition for the recovery. Nabors et $\mathrm{a}^{45}$ showed that fewer negative symptoms, greater metacognitive capacity, and higher self-esteem might be aspects that increase the stigma resistance. Yanos et $\mathrm{al}^{46}$ elaborated a narrative review of articles focused on interventions targeting self-stigma. They identified six approaches that discussed interventions specifically targeting self-stigma in patients with a severe mental illness. These interventions are different. Nevertheless, there are several common mechanisms employed. They use psychoeducation and information to counteract myths about mental disease, cognitive techniques that offer opportunities to learn and practice skills to identify and combat self-stigmatizing thoughts and beliefs, an emphasis on narration and its potential to help patients make sense and create meaning out of past experiences, and some degree of behavioral decision making, and they offer tools and experiences designed to increase or elicit hope, empowerment, and motivation to act toward one's goals according to one's values.

\section{Limitations of the study}

The current study has several limitations. In particular, it was not possible to explain the causality of the described correlations, because of the cross-sectional study design. The research sample of patients was relatively small. Another limitation was the fact that the data were collected through scales filled out by the patients themselves. The preponderance 
of the subjective judgment of the assessment methods, which are dependent on the ability of introspection of the patient and his/her willingness to testify, has its limitations, particularly in patients with schizophrenia who may have a considerable degree of cognitive dysfunction. Filling out the questionnaires also could have been modified by various levels of fatigue, current status, and motivation of the patients.

\section{Conclusion}

Stigma is a major social problem that significantly affects the quality of life of the patients with schizophrenia. Understanding the issue of self-stigma in practice can play a major role in the treatment of the patients with schizophrenia spectrum disorders, not only for a psychiatrist but also for other mental health professionals. The management of selfstigma in the patient's care should be given due attention. Changing negative stereotypical attitudes toward people suffering from mental disorders is an important task.

\section{Disclosure}

The authors report no conflicts of interest in this work.

\section{References}

1. Dickerson FB, Sommerville J, Origoni AE, Ringel NB, Parente F. Experiences of stigma among outpatients with schizophrenia. Schizophr Bull. 2002;28(1):143-155.

2. Lee S, Chiu MY, Tsang A, Chui H, Kleinman A. Stigmatizing experience and structural discrimination associated with the treatment of schizophrenia in Hong Kong. Soc Sci Med. 2006;62(7):1685-1696.

3. Gray AJ. Stigma in psychiatry. J R Soc Med. 2002;95(2):72-76.

4. Schulze B, Angermeyer MC. Subjective experiences of stigma: a focus group study of schizophrenic patients, their relatives, and mental health professionals. Soc Sci Med. 2003;56(2):299-312.

5. Dinos S, Stevens S, Serfaty M, Weich S, King M. Stigma: the feelings and experiences of 46 people with mental illness. Qualitative study. Br J Psychiatry. 2004;184:176-181.

6. Buizza C, Schulze B, Bertocchi E, Rossi G, Ghilardi A, Pioli R. The stigma of schizophrenia from patients' and relatives' view: a pilot study in an Italian rehabilitation residential care unit. Clin Pract Epidemol Ment Health. 2007;3:23.

7. Gonzalez-Torres MA, Oraa R, Aristegui M, Fernandez-Rivas A, Guimon J. Stigma and discrimination towards people with schizophrenia and their family members. A qualitative study with focus groups. Soc Psychiatry Psychiatr Epidemiol. 2007;42(1):14-23.

8. Corrigan PW, Wassel A. Understanding and influencing the stigma of mental illness. J Psychosoc Nurs Ment Health Serv. 2008;46(1): $42-48$.

9. Livingston JD, Boyd JE. Correlates and consequences of internalized stigma for people living with mental illness: a systematic review and meta-analysis. Soc Sci Med. 2010;71(12):2150-2161.

10. Corrigan PA, Watson AC, Barr L. The self-stigma of mental illness: implications for self-esteem and self-efficacy. J Soc Clin Psychol. 2006; 25:875-884.

11. Lebel T. Perceptions of and responses to stigma. Soc Comp. 2008;2: 409-432.

12. Werner P, Aviv A, Barak Y. Self-stigma, self-esteem, and age in persons with schizophrenia. Int Psychogeriatr. 2008;20(1):174-187.
13. Yanos PT, Roe D, Markus K, Lysaker PH. Pathways between internalized stigma and outcomes related to recovery in schizophrenia spectrum disorders. Psychiatr Serv. 2008;59(12):1437-1442.

14. Segalovich J, Doron A, Behrbalk P, Kurs R, Romem P. Internalization of stigma and self-esteem as it affects the capacity for intimacy among patients with schizophrenia. Arch Psychiatr Nurs. 2013;27(5): 231-234.

15. Collett N, Pugh K, Waite F, Freeman D. Negative cognitions about the self in patients with persecutory delusions: an empirical study of self-compassion, self-stigma, schematic beliefs, self-esteem, fear of madness, and suicidal ideation. Psychiatry Res. 2016;239:79-84.

16. Vidović D, Brecić P, Vilibić M, Jukić V. Insight and self-stigma in patients with schizophrenia. Acta Clin Croat. 2016;55(1):23-28.

17. Ritsher JB, Phelan JC. Internalized stigma predicts erosion of morale among psychiatric outpatients. Psychiatry Res. 2004;129(3):257-265.

18. Mashiach-Eizenberg M, Hasson-Ohayon I, Yanos PT, Lysaker PH, Roe D. Internalized stigma and quality of life among persons with severe mental illness: the mediating roles of self-esteem and hope. Psychiatry Res. 2013;208(1):15-20.

19. Trosbach J, Angermeyer MC, Stengler-Wenzke K. Zwischen einbezogensein und widerstand: angehorige im umgang mit zwangserkrankten. Psychiatr Prax. 2003;30:8-13.

20. Gerlinger G, Hauser M, De Hert M, Lacluyse K, Wampers M, Correll CU. Personal stigma in schizophrenia spectrum disorders: a systematic review of prevalence rates, correlates, impact, and interventions. World Psychiatry. 2013;12(2):155-164.

21. Birchwood M, Trower P, Brunet K, Gilbert P, Iqbal Z, Jackson C. Social anxiety and the shame of psychosis: a study in first episode psychosis. Behav Res Ther. 2007;45(5):1025-1037.

22. Tarrier N, Khan S, Cater J, Picken A. The subjective consequences of suffering a first episode psychosis: trauma and suicide behaviour. Soc Psychiatry Psychiatr Epidemiol. 2007;42(1):29-35.

23. Maxdorf Praha. Mezinárodni klasifikace nemoci - 10. revize, $M K N-10$ [International Classification of Diseases - 10th revision] (1. vydáni). Praha: Maxdorf; 1996.

24. Ritsher JB, Otilingam PO, Grajales M. Internalized stigma of mental illness: psychometric properties of a new measure. Psychiatry Res. 2003; 121:31-49.

25. Boyd JE, Adler EP, Otilingam PG, Peters T. Internalized Stigma of Mental Illness (ISMI) Scale: a multinational review. Compr Psychiatry. 2014;55(1):221-231.

26. Ocisková M, Praško J, Kamarádová D, et al. Self-stigma in psychiatric patients - standardization of the ISMI scale. Neuro Endocrinol Lett. 2014;35(7):624-632.

27. Guy W, editor. ECDEU Assessment Manual for Psychopharmacology. Rockville, MD: DHEW; 1976.

28. European Medicines Agency. Guideline for good clinical practice. July 2002. Available from: http://www.edctp.org/fileadmin/documents/ EMEA_ICH-GCP_Guidelines_July_2002.pdf. Accessed May 19, 2016.

29. Ceskova E, Prikryl R, Pec O. Schizofrenie u dospělých. In: Raboch J, Uhlikova P, Hellerova P, Anders M, Susta M, editors. Psychiatrie. Doporučené postupy psychiatrické péče IV [Psychiatry. Recommended practices in psychiatric care IV]. Psychiatrická společnost ČSL JEP; 2014:44-51.

30. Ocisková M, Praško J, Látalová K, et al. Internalizované stigma a efektivita farmakoterapie a psychoterapie u úzkostných poruch a poruch neurotického spektra [Internalized stigma and efficacy of pharmacotherapy and psychotherapy in anxiety and neurotic spectrum disorders]. Čes a Slov Psychiat. 2014;110(3):233-243. Czech.

31. Vrbová K, Kamarádová D, Látalová K, et al. Self-stigma and adherence to medication in patients with psychotic disorders - cross-sectional study. Neuro Endocrinol Lett. 2014;35(7):645-652.

32. Ociskova M, Prasko J, Kamaradova D, et al. Coping strategies, hope, and treatment efficacy in pharmacoresistant inpatients with neurotic spectrum disorders. Neuropsychiatr Dis Treat. 2015;11: 1191-1201. 
33. Hajda M, Kamaradova D, Latalova K, et al. Self-stigma, treatment adherence, and medication discontinuation in patients with bipolar disorders in remission - a cross sectional study. Act Nerv Super Rediviva. 2015;5(1-2):6-11.

34. Kamaradova D, Latalova K, Prasko J, et al. Connection between selfstigma, adherence to treatment, and discontinuation of medication. Patient Prefer Adherence. 2016;10:1289-1298.

35. Holubova M, Prasko J, Latalova K, et al. Are self-stigma, quality of life, and clinical data interrelated in schizophrenia spectrum patients? A crosssectional outpatient study. Patient Prefer Adherence. 2016;10:265-274.

36. Grambal A, Prasko J, Kamaradova D, Latalova K, Holubova M, Sedlackova Z. Self-stigma in borderline personality disorder in comparison with schizophrenia, major depressive disorder, and anxiety disorders cross-sectional study. Patient Prefer Adherence. 2016;10:1421-1433.

37. Buckland HT, Schepp KG, Crusoe K. Defining happiness for young adults with schizophrenia: a building block for recovery. Arch Psychiatr Nurs. 2013;27(5):235-240.

38. Oliveira SE, Esteves F, Carvalho H. Clinical profiles of stigma experiences, self-esteem, and social relationships among people with schizophrenia, depressive, and bipolar disorders. Psychiatry Res. 2015; 229(1-2):167-173.

39. Boyer L, Baumstarck K, Boucekine M, Blanc J, Lançon C, Auquier P. Measuring quality of life in patients with schizophrenia: an overview. Expert Rev Pharmacoecon Outcomes Res. 2013;13(3):343-349.

40. Lysaker PH, Vohs J, Hillis JD, et al. Poor insight into schizophrenia: contributing factors, consequences, and emerging treatment approaches. Expert Rev Neurother. 2013;13(7):785-793.
41. Lysaker PH, Buck KD, Salvatore G, Popolo R, Dimaggio G. Lack of awareness of illness in schizophrenia: conceptualizations, correlates, and treatment approaches. Expert Rev Neurother. 2009;9(7): 1035-1043.

42. Lysaker PH, Vohs J, Hasson-Ohayon I, Kukla M, Wierwille J, Dimaggio G. Depression and insight in schizophrenia: comparisons of levels of deficits in social cognition and metacognition and internalized stigma across three profiles. Schizophr Res. 2013;148(1-3):18-23.

43. Lysaker PH, Roe D, Ringer J, Gilmore EM, Yanos PT. Change in selfstigma among persons with schizophrenia enrolled in rehabilitation: associations with self-esteem and positive and emotional discomfort symptoms. Psychol Serv. 2012;9(3):240-247.

44. Firmin RL, Luther L, Lysaker PH, Minor KS, Salyers MP. Stigma resistance is positively associated with psychiatric and psychosocial outcomes: a meta-analysis. Schizophr Res. 2016;175(1-3):118-128.

45. Nabors LM, Yanos PT, Roe D, et al. Stereotype endorsement, metacognitive capacity, and self-esteem as predictors of stigma resistance in persons with schizophrenia. Compr Psychiatry. 2014;55(4):792-798.

46. Yanos PT, Lucksted A, Drapalski AL, Roe D, Lysaker P. Interventions targeting mental health self-stigma: a review and comparison. Psychiatr Rehabil J. 2015;38(2):171-178.
Neuropsychiatric Disease and Treatment

\section{Publish your work in this journal}

Neuropsychiatric Disease and Treatment is an international, peerreviewed journal of clinical therapeutics and pharmacology focusing on concise rapid reporting of clinical or pre-clinical studies on a range of neuropsychiatric and neurological disorders. This journal is indexed on PubMed Central, the 'PsycINFO' database and CAS,

\section{Dovepress}

and is the official journal of The International Neuropsychiatric Association (INA). The manuscript management system is completely online and includes a very quick and fair peer-review system, which is all easy to use. Visit http://www.dovepress.com/testimonials.php to read real quotes from published authors. 